\title{
A Study on Human Resource Perspectives of Emotional Labour in Service Sector.
}

\author{
B.Renuka Devi, \\ Research Scholar, Department of Business administration, Khadir Mohideen college, Adirampattinam, Tamil \\ nadu.
}

\begin{abstract}
Emotional labor, the process of regulating both, feelings and expressions for organizational goals, is commonplace in the hospitality industry. Past research has constantly provided empirical evidence that emotional labor can have positive consequences on organizational success but negative impact on employees' well-being. Within the context of the Indian service industry, this paper discusses the concept and consequences, of emotional labor and how important it is for organizations to acknowledge their workers' emotional contribution to the organizational performance. Some suggestions in terms of human resources (HR) practices to assist service employees provide quality service while dealing more effectively with the strain associated with the performance of emotional labor are also offered.
\end{abstract}

Keywords: Emotional Labour, Hospitality Industry, Human Resource practice.

\section{Introduction}

Identified as one of Malaysia's key industries with great potential for growth, the tourism, industry accounted for 7 per cent of Indian economy in the year 2005 (Asia Times, 2005). This industry is entirely dependent on the hospitality industry which is a significant employer, with lodging/services playing a critical role (Page \& Connell, 2006). In 2004, the Indian Service Association (IHA) Sabah Chapter was launched with the aim to further improve the quality of services in the service industry for Sabah and the Federal Territory of Labuan (Labuan).

We opine that to facilitate the development and improvement of the service industry in Malaysia as a whole, and notably in Labuan, injecting funding into the sector alone is hot enough. Quality manpower that can provide world-class services remains the key determinant' of the industry's success and continued growth. As such funding efforts will go to waste if they are not accompanied by effective human resources (HR) practices in terms of selection, training, and compensation of the service workforce. One area worthy of close attention is how service employees manage their emotions in the workplace and the outcomes of the process. The emphasis on emotion management is particularly pertinent given the fact that to remain courteous and friendly even-when having to deal with demanding and difficult customers is part and parcel of service employees'jobs.

In light of the aforementioned, the objective of this paper is three-fold: (a) to provide a better understanding of the concept of emotional labor and its consequences; (b) to bring greater awareness to the service industry of their employees' emotional contribution to the organizational performance; and (c) to suggest several HR practices that the service industry can employ to assist their workers in the management of emotional labor. The paper begins by clarifying the concept of emotional labor before it proceeds to discuss the impact of emotional labor on the organization and employees. Finally, within the context of emotion management in the service industry, it discusses several HR practices in the areas of employee selection, training and development, and compensation.

\section{Overview of emotional labor}

With awareness and realizations about work based emotions escalating, research in the area of emotions is done primarily under work or social settings. Over the years, the scope of this research has broadened itself to lead us to a newer concept of "Emotional Labor". Emotional Labor, as advocated by Arlie Hochschild is all about 'the management of feeling to create a publicly observable facial and bodily display for a wage'. To start with, emotional labor research started exploring role related aspects. The role based research reviewed "role sending" and "receiving" and the psychological presence of the employee during the actual performance in the role becomes a major determinant in deciding the effectiveness of the role outcomes. (Kahn, 1990) further emphasizes that people can use varying degrees of their selves, physically, cognitively, and emotionally, in the roles they perform, even as they maintain the integrity of the boundaries between who they are and the roles they occupy. This leads to the momentary role attachment and detachment. Research in the area of Emotional Labour and Role based interactions has constantly identified the concomitant linkages between the two. Over the years Emotional Labor research has graduated itself from a mere qualitative approach to a more reliable quantitative approach. The more recent of the researches by (Yagil \& Liraz, 2013) have 
focused on psychological autonomy that enhances behavioural expression of authenticity. Authenticity during service encounters can result in dedication, positive emotions, and good interaction with customers. The scope of this research has extended itself to consider some of the uncommon professions to conduct a variety of interesting studies. The professions range from adventure guides (Sharpe, 2005; Torland, 2013), flight attendants (Williams, 2003), fast-food employees (Tan, Foo \&Kwek, 2004), hotel employees (Hwa, 2012), call centre employees (Zapf et. al., 2003), waitresses (Paules,1991), amusement park employees (Van Maanen\&Kunda, 1989), cashiers(Rafaeli\& Sutton, 1987), 911 dispatchers (Shuler \&Sypher, 2000), police officers(Martin, 1999),Construction professionals (Lingard\& Francis, 2005), Health care workers (Karl \&Peluchette, 2006; Lewis, 2012), Teaching professionals (Naring, Briet\&Brouwers, 2006) to name a few.

\section{The Consequences of Emotional Labor}

Previous work in the area of emotional labor consistently supports the notion proposed by Hochschild (1983) that emotional labor does and can have both functional and dysfunctional consequences for the individual and the organization. Hochschild (1983) propounds that emotion management is detrimental to service employees because their emotions are now mandated by the organization. Conversely, the regulated emotional display is thought to benefit the organization. Kim (2008) similarly regards emotional labor to have double-edged effects: It can have positive influence on organizational success but negative impact on employees' well-being.

With respect to the contribution of emotional labor to organizational success, there has been a growing connection of emotional labor to economic trends (Zeithaml, Parasuraman, \& Berry, 1990) Specifically, it has been reported that emotional labor positively influences perception of service quality (Bowen, Siehl, \& Schneider, 1989), customer loyalty, repeat business, financial gains (Heskett, Schlesinger, \& Sasser, 1997), client satisfaction, and organizational productivity (Meier, Mastracci, \& Wilson, 2006). Previous work has also documented that emotional labor negatively affects workers' well-being (Johnson \& Spector, 2007), job satisfaction (Ang, Rostinah, Japang, \& Nasah, 2009; Jones, 1998; Yang \& Chang, 2008), organizational commitment (Abraham, 1999; Yang \& Chang, 2008), and increases emotional exhaustion (Ang et al., 2009; Johnson \& Spector, 2007; Kim, 2008), intent to leave (Abraham, 1999), turnover (Meier et al., 2006), and workfamily conflict (Seery, Corrigall, \& Harpel, 2008). Generally, the influence of emotional labor on employee outcomes such as health, psychological well- being and work attitudes has generally been reported to be less favorable. However, some studies (e.g., Adelmann, 1995; Johnson, 2004; Wharton, 1993) have reported otherwise. For instance, Wharton (1993) did not find a negative relationship but a positive relationship between emotional labor and job satisfaction. Wharton's (1993) argument is that the positive or negative outcome of emotional labor on employee outcomes depends on the performance technique which the employee chooses to use. What this means is that suppressing negative, emotions (i.e., surface acting) is detrimental to employees' wellbeing (Gross, 1989; King \& Emmons, 1990; Smith, 1992), whereas the expression of positive emotions (i.e., to deep acting) may in turn enhance employees' well-being (Zajonc, 1985),

Even though empirical findings of these relationships remain conflicting (Van Dijk \& Kirk, 2006), the majority of past research has evidenced that deep acting leads to more favorable outcomes than does surface acting (Kim, 2008). Collectively, these findings hold important implications to the service industry in terms of HR practices. The next section discusses these practices in greater detail.

Effective Human Resource Practices: Some Recommendations

The service occupational norms, best typified, with the cliche "service with a smile", necessitate hospitality workers to perform emotional labor to achieve organizational goals. Even when having to deal with demanding and difficult customers, these employees are expected to remain courteous and friendly as part of satisfying customers and providing quality service. Yet, in doing so, they directly subject themselves to the negative consequences of emotional labor such as decreased job satisfaction, increased intention to quit, workfamily conflict, and emotional exhaustion. Considering the detrimental effects of emotional labor on employees' well-being and work outcomes', service employers need to reexamine their HR practices to deal with such situations. These HR practices will be discussed in three broad areas of selection, training and development, and compensation.

\section{Selection}

Selecting the right people for the job is crucial for employee performance simply because employees with, the right skills will do a better job for the company. Thus, service employers can make use of various selection tests and techniques such as aptitude and personality tests. In context of the service industry, emotional intelligence test will be particularly relevant since it has been reported that effective management of workplace emotions, particularly using deep acting technique, requires high levels of EI (McShane \& Yon Glinow, 2010). This is because higher levels of EI indicate greater ability to regulate emotions in oneself and in others (McShane \&Von Glinow, 2010). 
Personality tests are also useful for the selection of service employees as past studies have demonstrated that high positive affectivity people are capable of performing emotional labor in a genuine way (Chu, 2002). But when services want to hire high positive affectivity people for their ability to provide quality and sincere hospitality, the companies also.risk losing these people because of their propensity to experience emotional exhaustion more quickly (Chu, 2002). Also, when jobs require high levels of emotional labor, training plays a more crucial role than selection. As such, it is perhaps more important for services to reconsider their employee-training and development programs that can help develop the necessary skills to perform emotional labor. This requires more concerted efforts by service employers to design effective training programs than relying on selection alone

\section{Training and Development}

Emotional labor training will assist employees when dealing with stressful guest transactions in a calmer .manner to achieve better quality service. Such training can be divided into 3 categories: (a) orientation program; (b) on-going training program; and (c) stress management program. In implementing these training programs, we propose the use of behavior modeling training, a training technique that has been reported to be "one of the most widely used, well researched, and highly regarded psychologically based training interventions" (Taylor, Russ-Eft, \& Chan, 2005). Essentially, the procedure is comprised of modeling, role playing, social reinforcement, and transfer of training. To elaborate, employees are first shown good emotion management techniques, are asked to play employee-customer roles in simulated situation, and are then given feedback and praise by their supervisor or trainer (McShane \& Von Glinow, 2010).

Targeting at new recruits, orientation programs are used to convey appropriate attitudes and display rules. The focal point of such program is on customers' feelings-how to make them feel comfortable and welcomed. While it is still acceptable that the emphasis is on customers ${ }^{3}$ and not employees' emotions at this stage, the service needs to be aware of the fact that eventually employees will be vulnerable to the negative consequences of emotional labor. Hence, training programs must also at some point focus on employees' feelings and well-being in order to provide the opportunity for employees to discuss their feelings and how to more effectively manage their emotions.

This type of employee-focus training has several weighty benefits. First, it signals to the employees that the management is aware of and acknowledges the emotional contribution that they put into the jobs (Chu, 2002). By extension, employees' .motivation and productivity on the job will be enhanced. Second, it provides the opportunity for employees to ventilate their negative emotions caused by their jobs. But more importantly, such training can develop in employees the ability to handle their anger and frustrations. To illustrate, we cite the words of a trainer for. such training program for flight attendants; "If a passenger snaps at you and you didn't do anything wrong, just remember it's not you he is snapping at. It's your uniform; it's your role as a Delta flight attendant. Don't take it personally" (Hochschild, 1983, p. no].

On-going training programs will be an extension of the orientation programs. However,. the emphasis would be to help employees how to perform deep acting - the emotional labor technique that has been consistently reported to result in more favorable outcomes for employees (e.g., increased job satisfaction and decreased emotional exhaustion) and ' organizations alike (e.g., increased customer satisfaction and sincere hospitality). Chu (2002) propounds the importance of integrating deep acting into training to carefully regulate the internal processes of emotional management so that external emotional expressions will appear to be more genuine and spontaneous. In addition, this type of training provides an excellent opportunity for employees to discuss their feelings and frustrations on their jobs, particularly when they are hurt or insulted by difficult guests. It should also be noted that such training should not be for front-line employees only but also for managers since the latter typically experience higher levels of emotional labor having to deal with both subordinates and customers (Chu", 2002). Both front-line employees and their managers can talk over negative emotions and exchange tips about expressing them in less offensive manners. Formal training programs for managers can incorporate modules such as "how to provide emotional support," "how to handle employee complaints," and "how to provide constructive feedback and opinions" (Chu, 2002).

Past studies (e.g., Ang et al., 2009; Johnson, 2004) have found gender to influence the choice of acting method such that females tended to employ more deep acting when compared to their male counterparts. Hence, training and education in emotion management should also be gender-specific. Men may need more training in this aspect (Grandey, 2000).

Performing emotional labor is stressful, particularly with the use of surface acting. Research (e.g., Ang et al., 2009; Johnson \& Spector, 2007; Kim, 2008) has in fact reported that emotional labor can result in emotional exhaustion. Emotional exhaustion is a stress outcome that occurs when an employee is in the state of depleted energy (Jackson, Schwab, \& Schuler, 1986). Hence, the final type of program should be aimed at helping service employees deal with the strain associated with emotional labor more effectively. Stress management programs should adopt emotion-focused coping rather than the problem-focused coping approach 
to deal with stressors. The former approach is the steps taken by an employee to address and alleviate stressful feelings and emotions, whereas the latter refers to the actions taken directly with the source of stress (Ivancevich, Konopaske, \& Matteson, 2008). The benefits of emotion-focused strategies include meditation, biofeedback, exercise, joining a work support group, and personal off days (Ivancevich et al., 2008).

\section{Compensation}

As noted earlier, emotional labor is important in influencing customer satisfaction and is equally significant in affecting the bottom line. Lamentably, employees' emotional contribution has not been accordingly acknowledged by the management. Whereas mental and physical labor gets compensated fairly well, emotional labor performers in the service industry seem to receive relatively lower wages (Chu, 2002). Hence, establishing-strategic pay plans is a very crucial management agenda. The central point is that when service employees successfully deep act to provide quality, and genuine service, they need to be not only recognized but also rewarded for their efforts.

That being said, if service employers in Labuan and Sabah can start redesigning their pay structures to properly recognize the emotional contribution made by their workers, perhaps the issue of losing skilled and experienced workers to other countries that promise more attractive wages can be dealt with more aptly. Additionally, competitive compensation structure can pose as ah effective means to attract more quality candidates to the Indian service industry.

\section{Conclusion}

The role and importance of emotional labor in the service industry setting has been elucidated in this paper. The paper has also argued that effective HR practices,have to be in place should Indian services want to attract as well as retain high quality workforce. In essence, the management needs to create conditions for satisfying work and less stressful, work environment for employees. Equally necessary is for managers to regulate or monitor employees' behavior or emotional expressions to ensure service quality. The use of formal or informal means to ventilate employees ${ }^{1}$ anger and frustrations on the job is also of utmost importance. If not, sooner or later, the employees "will start to express their anger to the customers or subsequently leave the jobs. On a final note, the responsibility of implementing effective HR practices lies with every manager-not just those in human resources (Dessler, 2008).

\section{References}

[1] Bakker B. Arnold, Demerouti Evangelia \& Schaufeli B. Wilmar (2003). Dual processes at work in a Call centre: An Application of the job demands - resources model. European Journal of Work \& Organizational Psychology, 12(4), 393-417.

[2] Biron Caroline, Brun Jean-Pierre \& Ivers Hans (2008). Extent and sources of occupational stress in university staff. Work, 30, 511522 .

[3] Brannan J. Matthew (2005). Once more with feeling: Ethnographic reflections on the mediation of tension in a small team of call centre workers. Gender, Work \& Organization, 12(5), $420-439$.

[4] Brief, A.P. and Weiss, H.M. (2002). Organizational behaviour: Affect in the workplace. Annual Review of Psychology, 53, 279307.

[5] Bulan, H.F., Erickson, R. and Wharton, A.S. (1997) Doing for others on the job: the effective requirements of service work, gender and emotional well-being, Social Problems, 44(2), pp.235-57.

[6] Cohen. J. (1988). Statistical power analysis for the Behavioural sciences (2nd ed.). Hillsdale, NJ: Lawrence Erlbaum.

[7] Curtis R. Catherine \& Upchurch S. Randall (2008). A Case study in establishing a positive service culture: Attachment and involvement in the workplace. Journal of Retail \& Leisure Property, 7(2), 131-138.

[8] Dougherty, D. S. \& Drumheller, K. (2006). Sensemaking and emotions in organizations: Accounting for emotions in a rationalized context. Communication Studies, 57, 215-238.

[9] Gosserand H. Robin \& Diefendorff M. James (2005). Emotional Display Rules and Emotional Labour: The Moderating Role of Commitment. Journal of Applied Psychology, 90(6), 1256-1264.

[10] Grandey, A. A. (2000). Emotion regulation in the workplace: A new way to conceptualize emotional labor. Journal of Occupational Health Psychology, 5, 95-110.

[11] Groves K and Vance C. (2009). Examining thinking style, EQ and Organizational commitment. Journal of managerial issues, 21(3), 344-366.

[12] Harris C. Lloyd (2002). The Emotional Labour Of Barristers: An Exploration Of Emotional Labour By Status Professionals. Journal of Management Studies, 39(4), 553-584.

[13] Hayes, S. and Kleiner, B.H. (2001) The managed heart: the commercialisation of human feeling - and its danger, Management Research News, 24(3/4), pp.81-5.

[14] Hochschild, A.R. (1983) The Managed Heart: Commercialization of Human Feeling. Berkeley: University of California Press.

[15] Hwa Magdalene Ang Chooi. (2012). Emotional Labor and Emotional Exhaustion Does Co-worker Support Matter? Journal of Management Research, 12(3), 115-127.

[16] Inigo et. al. (2007). Emotional Labour and Emotional Exhaustion: Interpersonal and Intrapersonal Mechanisms. Work \& Stress, 21 (1), 30-47.

[17] Kahn A. William (1990). Psychological Conditions of Personal Engagement and Disengagement at Work. Academy of Management Journal, 33(4), 692-724.

[18] Karl A. Katherine \& Peluchette V. Joy (2006). Does Workplace Fun Buffer the Impact of Emotional Exhaustion on Job Dissatisfaction? A Study of Health Care Workers. Journal of Behavioral \& Applied Management, $128-141$.

[19] Leinder, R. (1993). Fast food, fast talk: Service work and the routinization of everydaylife. Berkeley: University of California. 
[20] Lewig K. A. \& Dollard M. F. (2003). Emotional dissonance, Emotional exhaustion and Job satisfaction in call centre workers. European Journal of Work \& Organizational Psychology, 12 (4), 366-392.

[21] Lewis Lydia (2012). 'It’s People's Whole Lives': Gender, Class and the Emotion Work of User Involvement in

[22] Mental Health Services. Gender, Work and Organization. 19 (3), 276-305. doi:10.1111/j.1468-0432.2009.00504.xgwao

[23] Lin Chu Kay Hei (2002). The Effects of Emotional Labor on Employee Work Outcomes. Retrieved from: http://scholar.lib.vt.edu/theses/available/etd-06302002-164031/unrestricted/Chuetd.pdf

[24] Lingard Helen \& Francis Valerie (2005). Does Work-family conflict mediate the relationship between Job schedule demands and Burnout in male construction professionals and managers? Construction Management \& Economics, 23, 733-745.

[25] Liu Yongmei, Perrewe L. Pamela, Hochwarter A. Wayne \& Kacmar J. Charles (2004). Dispositional Antecedents and Consequences of Emotional Labour at Work. Journal of Leadership and Organizational Studies, 10 (4), 12-25.

[26] Malhotra, Y. (2000). Knowledge Management and New Organization Forms: A Framework for Business Model Innovation. Information Resources Management Journal, 13(1), 5-14.

[27] Mann, S. (1997) Emotional labour in organizations, Leadership \& Organization Development Journal, 18(1), pp.4- 12.

[28] Martin Susan Ehrlich (1999). Police Force or Police Service? Gender and Emotional Labor. The Annals of the American Academy of Political and Social Science, 561(1), 111-126. doi: 10.1177/000271629956100108

[29] Michinov Nicolas (2005). Social Comparison, Perceived Control and Occupational Burnout. Applied Psychology - An International Review, 21 (4), 986-1010.

[30] Morris Andrew J \& Feldman C. Daniel (1996). The Dimensions, Antecedents and Consequences of Emotional Labour. Academy of Management Review, 54 (1), 99-118.

[31] Murray \& Rostis (2007). Who's running the machine? A Theoretical Exploration of Work Stress and Burnout of

[32] Technologically tethered workers. Journal of Individual Employment Rights, 12 (3), 249-263.

[33] Naring Gerard, Briet Mariette \& Brouwers Andre (2006). Beyond demand-control: Emotional Labour and Symptoms of Burnout in Teachers. Work \& Stress, 20 (4), 303-315.

[34] Pareek Udai \& Purohit Surabhi (2009). Training Instruments in HRD and OD. Third Edition, Tata Mc-Graw Hill Education.

[35] Paules, G. F. (1991). Dishing it out: Power and resistance among waitresses in a NewJersey restaurant. Philadelphia : Temple University Press.

[36] Payne Jonathan (2009). Emotional Labour and Skill: A Reappraisal. Gender Work and Organization, 16 (3), 348-367.

[37] Pravettoni G., Cropley M., Leotta S. N. \& Bagnara S. (2007). The Differential role of Mental rumination among Industrial and Knowledge workers. Ergonomics, 50 (11), 1931-1940.

[38] Rafaeli, A., \& Sutton, R. (1987). Expression of emotion as part of the work role. Academy of Management Review, 12, 23-37.

[39] Schaubroeck, J. and Jones, J.R. (2000) Anecdotes of workplace emotional labour dimensions and moderatorsof their effects on physical symptoms, Journal of Organisational Behaviour, 21, pp.163-83.

[40] Schneider et. al, (2005). Understanding organization-customer links in service settings. Academy of Management Journal, 48(6), 1017-1032.

[41] Scott Brent A, Barnes Christopher M. \& Wagner David T (2012). Chameleonic or consistent? A multilevel investigation of emotional labor variability and self-monitoring. Academy of Management Journal, 55(4), 905-926. http://dx.doi.org/10.5465/amj.2010.1050

[42] Sharpe K. Erin (2005). Going Above and Beyond: The Emotional Labour of Adventure Guides. Journal of Leisure Research, 31 (I), $29-5$.

[43] Shuler, S. \&Sypher, B. D. (2000). Seeking emotional labor: When managing the heart enhances the work experience. Management Communication Quarterly, 14, 50-89.

[44] Steinberg, R.J. and Figart, D.M. (1999) Emotional labour since The Managed Heart. ANNALS, Annals of the American Academy of Political and Social Science, 561, 8-26.

[45] Stevens Lorna (2012). "Feeling bodies" in marketing: Aesthetics, emotions and gender. The Marketing Review, 12(2), 141-159, http://dx.doi.org/10.1362/146934712X13366562572421

[46] Strazdins, L.M. (2000) Integrating emotions: multiple role measurement of emotional work, AustralianJournal of Psychology, 52(1), pp. 41-50.

[47] Sutton Robert I \& Rafaeli Anat (1988). Untangling the Relationships between Displayed Emotions and Organizational Sales: The Case of Convenience Stores. Academy of Management Journal, 31 (3), 461-487.

[48] Syed Jawad (2008). From Transgression to Suppression: Implications of Moral values and Societal norms on Emotional Labour. Gender Work and Organization, 15 (2), 182-201.

[49] Tan Hoon Hwee, Foo Der Maw\& KwekHui Min (2004). The Effects of Customer Personality Traits on the Display of Positive Emotions. Academy of Management Journal, 47 (2), 287-296.

[50] Torland, M. (2013). Emotional labour and the job satisfaction of adventure tour leaders in Australia. PhD thesis, Southern Cross University, Lismore, NSW. Retrieved from http://epubs.scu.edu.au/cgi/viewcontent.cgi?article=1305\&context=theses

[51] Van Maanen, J., \&Kunda, G. (1989). Real feelings: Emotional expression and organizational culture. In L. Cummings \& B. Staw (Eds.), Research in organizational behavior(pp. 43-103). Greenwich: JAI.

[52] Welch, J. (1997) Forced smiles gloss over hidden trauma: employees who fake their emotions, People Management, 3, p.15.

[53] Williams Claire (2003). Sky Service: The Demands of Emotional Labour in the Airline Industry. Gender, Work \& Organization, 10 (5), 513-550.

[54] Yagil Dana and Liraz Medler Hana. (2013). Moments of Truth: Examining Transient Authenticity and Identity in Service Encounters. Academy of Management Journal, 56(2), 473-497. Retrieved from http://dx.doi.org/10.5465/amj.2011.0252

[55] Zapf, D. (2002) Emotion work and psychological well-being - a review of the literature and some considerations, Human Resource Management Review, 12(2), pp.237-68.

[56] Zapf Dieter, Isic Amela, Bechtoldt Myriam \& Blau Patricia (2003). What is typical for call centre jobs? Job characteristics, and Service interactions in different Call centers. European Journal of Work \& Organizational Psychology, 12 (4), 311-340.

[57] Zapf Dieter, Vogt Christoph, Seifert Claudia, Mertini Heidrun \& Isic Amela (1999). Emotion Work as a Source of Stress: The Concept and Development of an Instrument. European Journal of Work \& Organizational Psychology, 8 (3), 371-400. 